quality of milk; but emphasized the very serious difficulties under which the present-day dairy farmer is labouring.

The present state of our knowledge regarding certain major microbiological problems of the food canning industry was discussed by Mr. T, E. Bashford (London). The ideal heat process for any given canned food is one which, while of sufficient duration and temperature to render the product 'commercially sterile', yet has a minimal effect on its quality, nutritional value and on the attractiveness of its flavour. 'Commercial sterility' does not mean absolute sterility, since the finished pack may contain viable spores of thermophilic bacteria which do not give rise to difficulties so long as the cans are marketed under ordinary conditions of climate. Two main factors determine the adequacy of a process, namely, the rate of penetration of heat into the least accessible part of the contents of the can, and the thermal death-time of the most resistant of the organisms capable of causing spoilage or danger to health. The thermal death-time curve for $C l$. botulinum, the most heat-resistant and dangerous of the food-poisoning organisms, has been very carefully determined, and in practice it has been found normally satisfactory if the heat exposure, determined as regards temperature by that reached in the slowest-heating portion of the can, has a 'lethal value' about three times that needed to destroy $C l$. botulinum. In some cases, particularly where the pack has to go to tropical or semi-tropical countries, six to seven times the minimal lethal conditions for botulinum are used.

Mr. Bashford described how 'lethal rates and 'lethal values' are determined, and showed how accurate determination of temperatures, at any part of a can during processing, can be carried out by means of thermocouples inserted into the pack before autoclaving. He also dealt with post-processing infection of the can contents through minute holes which are sometimes left, particularly if the dimensions of cover and body do not conform to quite close mechanical tolerances, when the cans are being sealed. Organisms from the cooling water or from the air may be drawn through the defective seams as the internal pressure of the can falls during cooling. As a precautionary measure, chlorination of the cooling water is now extensively used in canneries, with marked reduction in the proportion of cans that become 'blown'. The importance was stressed of the highest possible degree of microbiological cleanliness, not only in the food and other raw materials, such as sugar, before canning, but also in the whole of the canning plant.

The realization by progressive millers and bakers of the same need for microbiological cleanliness was mentioned by Dr. E. C. Barton-Wright, who gave an interesting account of some microbiological aspects of flour-milling and baking. Beginning with the quorn, which was a type of property having a very special legal position in ancient society, Dr. BartonWright spoke of the evolution of power-driven mill stones and then of the sudden change, some seventy years ago, to the equivalent but fundamentally very dissimilar machinery which, with further modifications, carries out the modern, complicated process of flour milling. The all-important factor in the prevention of microbiological spoilage of wheat or flour is the moisture content, and experimental work in this field was described in some detail. Whereas wheat can be stored for long periods with complete safety at moisture content less than 16 per cent, with flour the conditions are more complex. Though moulds do not grow in flour which has a moisture content of less than 16 per cent, they nevertheless remain metabolically active when the moisture content is between 16 and 14 per cent, and will attack first the saturated acids and later the un. saturated fatty acids in the fat or oil naturally present in the flour, with disastrous results as regards baking quality and flavour. The metabolic activity of the moulds ceases below about 14 per cent moisture, but there is a danger of oxidative rancidity setting in if the moisture content is too far reduced, particularly in high-extraction flours. It is better, therefore, to store flour at a moisture content between 11 and 12 per cent, when the keeping life of a strong white flour under reasonably cool conditions may be as long as ten years. Even high-extraction flours, for example, National flour of 85 per cent extraction, will keep its quality under these conditions for several months.

Dr. Barton-Wright discussed the conditions controlling the growth of moulds on and in baked loaves. Mould infection is almost always external, and simple precautions in the bakehouse, the delivery van and the home should prevent it. The methods of prevention of the troublesome bacterial disease of bread known as 'rope', usually caused by B. subtilis spores in the flour which are not destroyed by the baking process, was described. More acid conditions during baking tend to prevent, and less acid conditions to foster, an outbreak of 'rope'.

A lively discussion followed, in which Mr. C. Ash (Coventry), Dr. J. Sword (Glasgow), Mr. D. H. F. Clayson (London), Mr. Hooper (Bristol) and others took part. It ranged over the effect of mastitis on milk quality, the alleged maldistribution of feeding stuffs for milk production, the absence of 'rope' in Scotland as a result of the more acid doughs used there, and the occasional presence in canned and preserved food of heat-stable toxins of bacterial origin.

\section{WAR-TIME DEVELOPMENTS IN METALS AND ALLOYS}

$T$ HE tenth Edward Williams lecture to the Institute of British Foundrymen was given by Sir Edward Appleton on "New Metals for Old". After a general discussion of the metallic state, Sir Edward discussed a numbor of aspects of metallurgy on which now light had been thrown in recent years.

The development of materials for war purposes has led to the introduction of new alloys, of which a steol containing carbon 0.4 per cent, nickel 13.5 per cent, chromium 13.5 per cent, tungsten $2 \cdot 5$ per cent, molybdenum 1.8 per cent, cobalt 10.5 per cent, niobium $3 \cdot 4$ per cent, may be mentioned as typical. This steel, developed for high-temperature services in the gas turbine, has a creep-rate of 0.2 per cent in 100 hours under a load of 5 tons per square inch at $800^{\circ} \mathrm{C}$. Improvements in the nickel-chromium alloys have been effected by the addition of titanium, which brings about a dispersion of particles of titanium carbide. Nichrome is also improved from the point of view of creep resistance by the precipitation of a complex intermetallic compound of nickel, titanium and aluminium.

An iron-nickel alloy with 36 per cent of nickel and 5-8 per cent of chromium, together with a certain 
amount of titanium, has been developed where low thermal expansion, as, for example, in a tuning fork, is required. The magnetic properties of iron-silicon alloys used in transformers, etc., have been shown to be effected by the crystalline orientation of the grains. Better magnetic properties are found in a direction parallel to the edges of the cube than in any other, and a technique has been worked out to ensure that this orientation is, at any rate, largely obtained.

Another example of the development in magnetically soft material are the dust-cores' used in transformers and inductances for telecommunication work. Here, a constant permeability is desired. A reduction in the size of the particles greatly reduces the effective permeability, but stabilizes its value for different magnetic fields as well as reducing the loss due to eddy currents. A carbonyl iron in the form of spherical particles a few thousandths of a millimetre in diameter has been produced in Great Britain for the purpose.

Passing on to the magnetically hard materials, the enormous advances which have been made in this field were outlined; the value with some alloys of applying during the cooling a magnetic field which produces a large increase in the remanence in the direction of the applied field was pointed out. Here, as in the case of the anisotropic silicon-iron, it is important that the design should be such that the material is used in the favourable direction only.

In conclusion, what may be an extremely important development in cast iron was mentioned. This, in brief, is the treatment of the iron in such a way that the graphite formed is of the nodular type characteristic of black-heart malleable iron, which hitherto has only been possible after lengthy heattreatment.

F. C. T.

\section{THE ZOOLOGICAL RECORD}

THE appearance of volume 81 of the Zoological Record, dealing mainly with the literature of 1944 , is worthy of special notice, for this comprehensive bibliography of zoological literature has been pubfished regularly since its foundation in 1864. The Record is still mainly dependent on donations for its production, and until the Zoological Society of London assumed responsibility for its publication it underwent many changes in its direction which might have had a disastrous effect on a less hardy annual.

The object of the Record is to give a reference to every article or book of zoological importance throughout the world that has appeared in the previous year. During the War it was impossible to bring out the volumes to time, and at the moment there is a delay of nearly two years; but as soon as printing conditions are easier it is hoped to get back to the normal practice of completing the Record in the year following the literature to which it refers. The cost of producing such a work is, of course, far beyond the price at which it is sold, and it could scarcely hope to be self-supporting; but a further measure of support might be expected from professional zoologists, some of whom seem to be unaware of its existence. The complete volume, published at $£ 4$ (subscription rate $£ 35 \mathrm{~s}$.), is more suitable for libraries, university departments, etc.; but the sections are issued separately as soon as they are ready, and since their cost ranges from only $2 s$., in the case of the smaller groups, to 6s. for Aves, and a maximum of $15 s$. for Insecta, it should be possible for any zoologist to provide himself with the literature of the group in which he is specially concerned.

There is a mistaken impression that the Zoological Record is only of interest to the systematist, but it is also invaluable to the comparative anatomist, the embryologist and the field naturalist; and publications concerned in a general way with genetics, ecology, and other branches of zoology are also included.

Each reference is allotted to one of the twenty odd sections into which the Record is divided, and then dealt with under three hearlings : (1) Titles, containing complete references to all articles arranged in alphabetical order of the authors' names ; (2) Subject Index, giving a detailed analysis of the subjects dealt with in each article; and (3) Systematic Index, comprising a list of all the animals referred to in the section concerned, including those described as new forms, arranged in systematic order. This arrangement enables the reader to find the information regarding the current zoological literature of any group under the authors' names, under specific subjects, or under the scientific names of animals.

The nature of the service provided by the Zoological Record is illustrated in the following excerpt :

\section{TITLES.}

68.-ChRISTENSEN, J. F. The oocysts of coccidia from domestic cattle in Alabama (U.S.A.), with descriptions of two new species. J. Parasit. Urbana, 27, 1941, pp. 203-220. 2 pls. 1 text fig.

II. SUBJECT INDEX.

STRUCTURE.

SPOROZOA.

Eimeria spp. (including new) from American cattle, CHRISTENSEN, 66.

ECOLOGY.

PARASITISM: Hosts-

MAMMALIA : Bos taurus, intestine (U.S.A.): Eimerio alabamensis spp.n., E. subspherica spp.n. (Sporoz. Coccid.). CHRrsTens

ECONOMICS.

COCOIDIOSIS: Coccidiosis in U.S.A. cattle. CHRISTENSEN, 66. III. SYSTEMATIC INDEX.
4. SPOROZOA. (b) COCCIDIIDA.
Eimeria alabamensis, E. subspherica spp.n. (with key to other spp.) from cattle, U.S.A. CHRISTENSEN, $\mathbf{6 6}$.

It should be emphasized that donations to the Zoological Record are still quite inadequate, and further support is urgently required from institutions and individuals.

Edward Hindle

\section{FORTHCOMING EVENTS}

Tuesday, September 2-Tuesday, September 9 WORLD POWER CONFERENOE (at The Hague, Holland).-Conference on "Fuel Economy".

Friday, September 5

INSTITUTE of ECONOMIC ENGINEERING (at Cowdray H Hll, Henrietta Place, London, W.1), at 7 p.m.-Colonel Bernard Ungerson: "Personnel Selection: Army Experience in its relation to the Problems of sonnel Selection
Industry".

\section{APPOINTMENTS VACANT}

APpuICations are invited for the following appointments on or before the dates mentioned :

IeOTURER-IN-Charge, Chemistri Dhpartment, in the Technical Education Branch of the Department of Public Instruction, SydneyThe Official Secretary, New South Wales Government Offices, 56-57 Strand, London, W.C.2 (September 5).

LEOTCRER IN PHYsIos-The Secretary, University Offices, 38 North Bailey, Durham (September 6).

Assistant Leoturer in Physioal Geography, and an Assistant LECTURER IN CHEMISTRY - The Registrar, University College of Wales, Aberystwyth (September 6 )

LEOTORER IN CHEMISTRY, and a LEGTURER IN PHYSIOLOGY-The Principal, Central 'Technical College, Suffolk Street, Birmingham (September 6). 